\title{
Prevalence of upper limb pain and disability and its correlates with demographic and personal factors
}

Fidaa Almomani'

Alia A Alghwiri ${ }^{2}$

Ahmad H Alghadir ${ }^{3}$

Amal Al-momani ${ }^{4}$

Amir $|q b a|^{3}$

'Therapeutic Sciences, Faculty of Applied Medical Sciences, Jordan University of Science and Technology, Irbid, Jordan; ${ }^{2}$ School of Rehabilitation Sciences, The University of Jordan, Amman, Jordan;

${ }^{3}$ Rehabilitation Research Chair, College of Applied Medical Sciences, King Saud University, Riyadh, Saudi Arabia; ${ }^{4}$ Queen Rania Center, Amman, Jordan
Correspondence: Amir lqbal

Rehabilitation Research Chair, College of Applied Medical Sciences, King Saud

University, P.O. Box. 10219, Riyadh

I 1433, Saudi Arabia

Tel +966 I 4696010

Fax +966 I 4693589

Email ajamaluddin@ksu.edu.sa
This article was published in the following Dove Press journal: Journal of Pain Research

Purpose: The present study aimed to assess the prevalence of upper limb pain and disability and to investigate potentially correlated factors among university students in Jordan.

Methods: This was a cross-sectional questionnaire-based survey study that was conducted among university students. The upper limb pain and disability were assessed by the Disabilities of the Arm, Shoulder, and Hand (DASH) outcome questionnaire. The DASH outcome questionnaire was distributed to 2100 students from the population of 2 public and 2 private universities in the north of Jordan. Demographic and personal information were collected. Data were analyzed using descriptive statistics and linear regression analysis.

Results: A total of 1929 DASH outcome questionnaires were returned, with a high response rate of $91.86 \%$. The age of the subjects was between $18-28$ years ( $52 \%$ male; $48 \%$ female). The majority of subjects $(85.2 \%)$ used at least one smartphone. The majority of them had been using a smartphone for more than 5 years. The prevalence of upper limb pain and disability among university students was $24 \%$. Several factors were found to be significantly connected with upper limb pain and disability among university students, such as smartphone use, computer use, the presence of musculoskeletal problems, not living with their families, using public transport (bus), and daily housekeeping.

Conclusion: The results of this study can be used globally to promote the health and wellbeing of university students, improve their academic performance and future career. Identifying high-risk groups will assist in early identifications and prevention programs for upper limb pain and disability among university students.

Keywords: DASH questionnaire, upper limb disability, university students, electronics' users, prevalence, socio-demographic

\section{Introduction}

Upper limb disability due to musculoskeletal disorders is a common health problem in the general population ${ }^{1,2}$ and in patients in primary care. ${ }^{3}$ A systematic review, published in 2006, reported a prevalence of upper limb disorders that ranged between $2 \%$ and $53 \%$ in different populations, with higher rates in students and working individuals. ${ }^{2}$ Musculoskeletal complaints in the upper limb have been associated with specific disorders ${ }^{1}$ such as shoulder tendinitis, adhesive capsulitis, lateral epicondylitis, carpal tunnel syndrome, and de Quervain's disease or have been attributed to non-specific conditions. 3,4

Upper limb disorders have attracted increased attention worldwide because of their high economic burden on health care and their negative consequences on the 
quality of life of affected individuals. It has been reported that upper limb disability places a heavy burden on healthcare systems, as well as employers, due to sickness absence and healthcare costs. ${ }^{5,6}$ Moreover, the high prevalence rates and the outcomes of upper limb complaints on activities of daily living, well-being, social participation and career productivity highlight the importance of gaining insight into the associated factors of this public health problem.

Consequently, upper limb disability among different occupations has been extensively studied. ${ }^{7,8}$ The reasons for occupational upper limb disability mostly accepted between studies were job demands and psychosocial variables. ${ }^{9}$ Although the majority of employees have finished their university degree before being employed and may have residual upper limb disability problems from their undergraduate/graduate level, students currently in college are a populace that has gotten relatively little consideration in regards to upper limb disability. Importantly, early intervention at university level might have great potential in reducing the expenses at the occupational level.

Recent epidemiological researches have investigated several risk factors related with upper extremity pain and disability in different populations including college students. ${ }^{10-23}$ Working with high technologies and different occupational stressors are highly correlated with prevalence of upper limb pain and disability. Prolonged computer use has been observed to be significantly connected with musculoskeletal pain and discomfort in the overall public. ${ }^{24-26}$ However, technology advances nowadays expose young individuals to several factors, apart from computer use, which may affect their musculoskeletal system, such as massive use of smart phones and other psychosocial aspects, especially in college students who are prone to academic stress. ${ }^{27,28}$ Other factors are also reported including the presence of other musculoskeletal disorders, ${ }^{8,16,17}$ ways and hours of transportations, ${ }^{15}$ housekeeping efforts, ${ }^{19-21}$ type and hours of occupation, ${ }^{10-14,29,30}$ sleeping habits as well as different socio-demographic factors, ${ }^{23}$ such as age, sex, marital status, area of living and presence of social support ${ }^{31,32}$ etc.

Moreover, there are few articles that studied the prevalence of upper limb disability with the focus on college students. ${ }^{10-12}$ Some authors demonstrated upper extremity disorders in students reading specific subjects, such as engineering. ${ }^{13,14}$ Other studies evaluated the general musculoskeletal symptoms in college students. ${ }^{29,30}$ However, all of these studies focused on the effect of computer use as the main risk factor for musculoskeletal complaints and reported an alarming incidence of upper limb symptoms (41-81\%) among college students. ${ }^{11-14,24,29,30}$

Prolonged computer use has been observed to be significantly connected with musculoskeletal pain and discomfort in the overall public. ${ }^{24-26}$ However, technology advances nowadays expose young individuals to several factors, apart from computer use, which may affect their musculoskeletal system, such as massive use of smartphones and other psychosocial aspects, especially in college students who are prone to academic stress. ${ }^{27,28}$

Therefore, wider view of the factors associated with musculoskeletal disorders in college students is necessary, as they appear to be at higher risk of developing upper limb pain and disability. Exploring the prevalence of upper limb pain and disorders at the university level would provide us with an insight on their subsequent disabling effect at occupational level. As it appears that college students increasingly select computer-intensive occupations following graduation, complaints of upper limbs may have significant effects on their professional career and productivity. It is important to identify prognostic and risk factors, particularly modifiable factors that may influence management and intervention strategies. This would enable rehabilitation therapists to provide better advice to high-risk patients and could be useful in the development of targeted management strategies, as well as public and occupational health initiatives.

To the best of our knowledge, data about the prevalence of upper limb pain and disability and correlated risk factors among university students in Jordanian and Arab world is limited. Prevalence and correlated factors could be affected by culture, environment, geographical factors and other living situations related to specific population around the globe. $^{18,22,23,31,32}$ Therefore, the essential points of the present study were to obtain knowledge into the prevalence of upper limb pain and disability among a populace of university students and to explore the potential factors associated with upper limb pain and disability, as measured by the Disabilities of the Arm, Shoulder, and Hand (DASH) outcome questionnaire score.

\section{Methods}

\section{Design}

This was a cross-sectional study, applied descriptive-correlation methodology to assess variables related to upper limb 
pain and disability among university students. Figure 1 explained the study protocol for this study.

\section{Participants}

The participants of the present study were recruited from 2 public universities (Yarmouk University and Jordan University of Science and Technologies) and 2 private universities (Irbid University and Jadarah University), located in the north part of Jordan. The total number of students in the selected four universities was approximately 50,000. Those students were excluded from the study; who were pregnant; involved in regular sports, exercises, and par-time jobs; unable to understand and fill in the study questionnaire or the consent form; exhibited congenital physical deformity, malignancies, amputations, prosthesis (upper and/or lower limbs), or any disability that interfered with daily life activities.

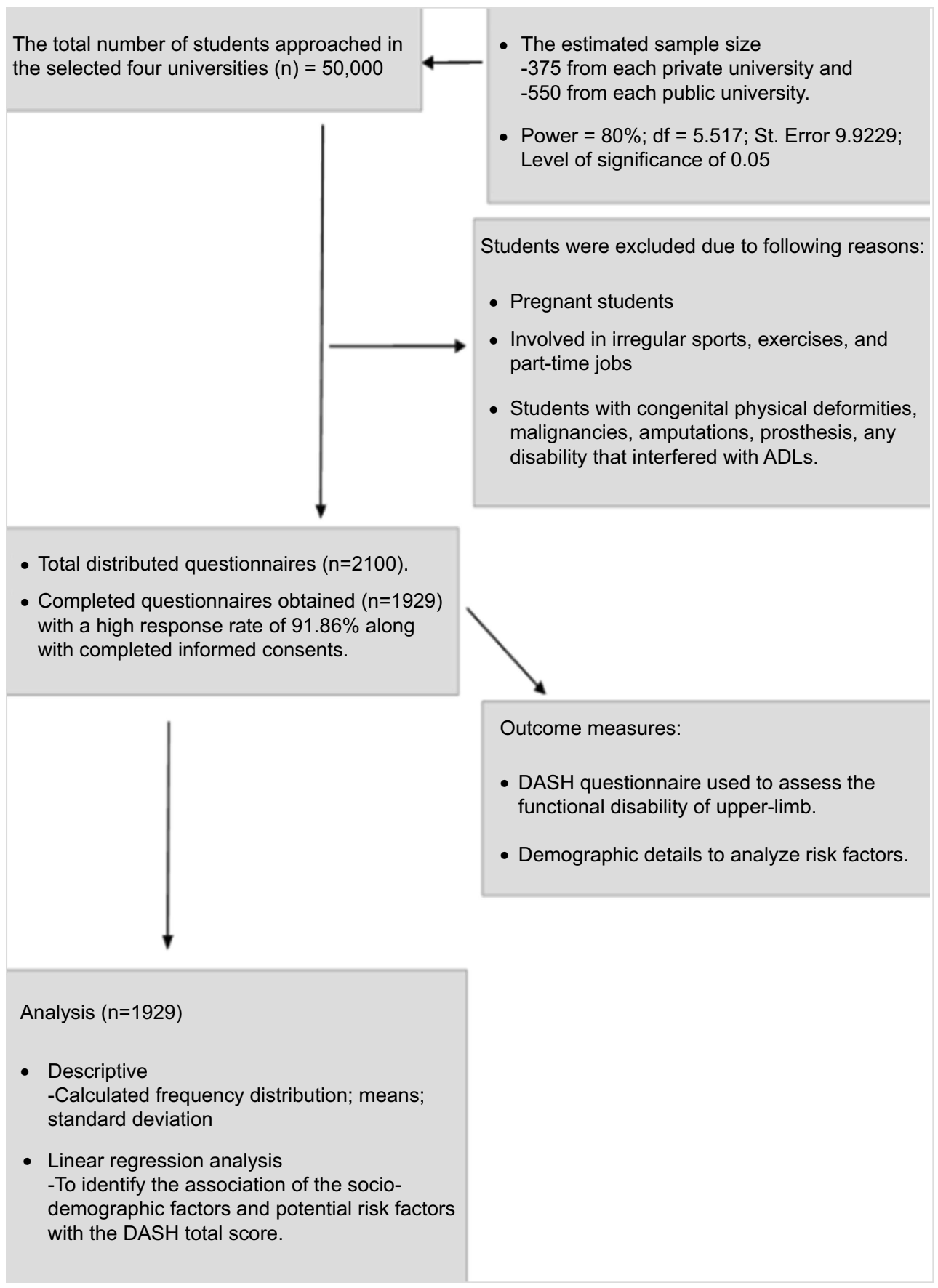

Figure I Flow chart of the study protocol.

Abbreviations: ADLs, Activities of daily livings; DASH, Disabilities of the Arm, Shoulder, and Hand. 


\section{Sampling and sample size calculation}

This study utilized a delegate sample of students from all academic years, including freshmen, junior and seniors, and final year, from all four universities. Power analysis was performed to calculate an adequate sample size. The estimated sample size was 375 students from each private university and 550 from each public university in order to achieve a power of $80 \%$ and a significance level of 0.05 .

\section{Procedures}

The study was approved by the institutional review board of our university hospital and the faculty of research at Jordan University of Science and Technology. The researcher randomly selected classes with large student number (>40 students) for participating in the study in order to ensure accurate processing of a large number of questionnaires, to guarantee smooth participation, and to achieve the best possible response rate. With permission of the instructor at each class, the researcher explained the purpose of the study, the content of the survey questionnaires and the inclusion and exclusion criteria. The questionnaires were immediately distributed by the researcher and completed by students. Prior to completing the questionnaire, students were asked to sign an informed consent form. In total, 2100 copies of the questionnaire were distributed to students in the 4 universities.

\section{Survey questionnaire}

The Arabic short version of the Disability of Arm, Shoulder, and Hand (DASH) Questionnaire was used in this study to estimate the prevalence and characterization of upper limb pain and disability. ${ }^{33}$ DASH is a 30 -item self-administered assessment tool that was developed to measure symptoms and physical functions of the upperextremity. Each item has a 5 ranking scale with 1 having "no difficulty" in performing the activity, 2 having "mild difficulty", 3 having "moderate difficulty", 4 having "sever difficulty" and 5 being "unable to do the activity". The overall score is calculated by adding up assigned values for each response to an item; divide by 30 (number of items); subtract 1 ; multiply by 25 . The overall score of the DASH ranges from $0-100$, in which a score of 0 means "no disability", a score of 50 means "moderate disability" and a score of a 100 means "maximum disability" in the upper limbs. ${ }^{33}$ It is a reliable and valid tool that can be used to assess one or more joints in upper extremity. It has very good psychometric properties. The Cronbach's alpha of the short Arabic version of the DASH was 0.94 with excellent test-retest reliability ( $\mathrm{ICC}=0.97$ ) and good construct validity with quality of life measures. ${ }^{34-36}$

Participants were also asked to complete a survey on socio-demographic factors (age, sex, marital status, area of living, living with or without the family/social support, and daily hours of sleep) and potential risk factors of upper limb disorders [presence of other musculoskeletal disorders, type of transportation to the university and hours spent on transportation, habits of laptop, computer and pencil/pen use, working hours (for working students), housekeeping effort, habits of phones use (number of years and daily hours of phone use, number of phones, the use of phone during transportation, single/both hand use of phone, phone usage before sleep, and reasons of using the phone (eg leisure, education or social communication), and depression/anxiety levels]. These factors have been found to be correlated with upper limb pain and disabilities. ${ }^{15-23,29-31}$

\section{Data processing and statistical analysis}

Data were analyzed using SPSS version 20 (SPSS ${ }^{\circledR}$ : Inc., Chicago, IL, USA). Descriptive statistics, including frequency distribution, means, and standard deviations were calculated. Furthermore, linear regression analysis was performed to identify the association of the socio-demographic factors and potential risk factors (independent variables) with the DASH total score (dependent variable). The B-value and t-value, and corresponding 95\% confidence intervals (CI) for all significant variables were calculated. The level of significance was set at 0.05 . For this sample, Cronbach's alpha coefficients as a measure of internal consistency for the Arabic version of the short form of DASH were calculated and found to be 0.943 .

\section{Results}

A total of one thousand nine hundred and twenty-nine (1929) DASH questionnaires were completed and returned, corresponding to a high response rate of $91.86 \%$. Students who participated in this study were between 18 and 28 years of age and almost equally distributed between both sexes ( $52 \%$ male). The socio-demographic and personal information of participants and the mean DASH score and standard deviations is shown in Table 1.

The mean DASH total score for the study sample was 31.63 ( $\mathrm{SD}=9.53$ ). The overall prevalence of mild-to-moderate upper limb disability in university students, based on the original DASH scores, was $24 \%$. 
Table I Socio-demographic and personal information ( $N=1929)$ with mean DASH score and standard deviations [M (SD)]

\begin{tabular}{|c|c|c|}
\hline Variable & $\mathbf{N}(\%)$ & $M(S D)$ \\
\hline \multicolumn{3}{|l|}{ Age (Years) } \\
\hline $18-20$ & $1215(63)$ & $30.6(8.9)$ \\
\hline $21-23$ & $370(19.2)$ & $30.8(9.6)$ \\
\hline $24-26$ & $284(14.7)$ & $3 I .1(10.2)$ \\
\hline$>26$ & $60(3.1)$ & $32.2(14.9)$ \\
\hline \multicolumn{3}{|l|}{ Sex } \\
\hline Male & $1011(52.41)$ & $30.9(9.7)$ \\
\hline Female & $918(47.59)$ & $31.2(10.2)$ \\
\hline \multicolumn{3}{|l|}{ Area of living } \\
\hline Urban & I I $48(59.5 \mid)$ & $28.73(10.2)$ \\
\hline Rural & $781(40.49)$ & $29.67(9.5)$ \\
\hline \multicolumn{3}{|l|}{ Marital status } \\
\hline Not married & I824 (94.6) & $29.03(9.8)$ \\
\hline Married & $105(5.4)$ & $30.62(12.1)$ \\
\hline \multicolumn{3}{|c|}{ Student lives with the family } \\
\hline Yes & $1566(81.2)$ & $26.95(9.05)$ \\
\hline No & $363(18.8)$ & $29.62(10.1)$ \\
\hline \multicolumn{3}{|c|}{ Working students } \\
\hline Yes & $4 \mid 2(2 \mid .4)$ & $29.99(9.8)$ \\
\hline No & $1517(78.6)$ & $28.88(9.9)$ \\
\hline \multicolumn{3}{|c|}{ Daily hours of work } \\
\hline $1-5$ & $173(9)$ & $28.92(9.9)$ \\
\hline $6-10$ & $190(9.9)$ & $29.82(9.2)$ \\
\hline$>10$ & $49(2.5)$ & $30.22(7.56)$ \\
\hline \multicolumn{3}{|c|}{ Daily hours of hand usage at work } \\
\hline $\mathrm{I}-4$ & $212(I I)$ & $29.56(10.3)$ \\
\hline $5-8$ & $167(8.7)$ & $30.62(11.1)$ \\
\hline$\geq 9$ & $33(1.7)$ & $31.47(15.3)$ \\
\hline \multicolumn{3}{|l|}{ Housekeeping } \\
\hline Yes & $1544(80)$ & $29.4(9.9)$ \\
\hline No & $385(20)$ & $28.12(10.9)$ \\
\hline \multicolumn{3}{|c|}{ Daily hours of housekeeping } \\
\hline $\mathrm{I}-2$ & $1111(57.6)$ & $29.63(10.3)$ \\
\hline $3-4$ & $338(17.5)$ & $34.07(15.6)$ \\
\hline$\geq 5$ & $95(4.9)$ & $37.71(17.7)$ \\
\hline \multicolumn{3}{|c|}{ Hours of daily sleep } \\
\hline $3-5$ & $294(I 5.2)$ & $30.7(12.0)$ \\
\hline $6-8$ & 1345 (69.7) & $29.85(10.2)$ \\
\hline$\geq 9$ & $290(15)$ & $29.17(11.5)$ \\
\hline
\end{tabular}

(Continued)
Table I (Continued).

\begin{tabular}{|l|l|l|}
\hline Variable & N (\%) & M (SD) \\
\hline \multicolumn{2}{|l|}{ Types of transportation used to university } \\
\hline Car & $395(20.5)$ & $28.37(10.1)$ \\
Public Transport (Bus) & $1444(74.9)$ & $33.37(9.9)$ \\
Walking & $79(4.1)$ & $28.89(9.8)$ \\
Motorcycle & $11(0.6)$ & $29.11(9.9)$ \\
\hline Daily hours in transportation & $1658(86)$ & $27.62(10.4)$ \\
\hline I-2 & $249(13)$ & $28.55(9.75)$ \\
$3-4$ & $22(1.1)$ & $29.64(9.9)$ \\
$\geq 5$ & $88(5)$ & $33.3(10.6)$ \\
\hline Presence of musculoskeletal disease & $29.0(9.9)$ \\
\hline Yes & $1841(95)$ & \\
No & \multicolumn{2}{|l}{} \\
\hline
\end{tabular}

\section{Characterization of the use of computer and telephone}

As presented in Table 2, the majority of subjects (85.2\%) used at least one smartphone, and a significant proportion of participants had been using a smartphone for 5 years or longer. The percentage of participants who reported using a smartphone before going to sleep was $90.8 \%$, while the percentage of students who reported using a smartphone during transportation was $82.1 \%$. More than two third of the students used a smartphone for leisure activities and social communications ( $63.8 \%$ and $67.3 \%$ respectively). The majority of participants (64.2\%) reported using a single hand during smartphone use, as compared with two hands. Regarding the daily hours of phone usage, $38.6 \%$ of participants reported 4 to $6 \mathrm{hrs}$, while $43 \%$ of students spend 1-2 hrs daily using a computer. Additionally, the majority of students (57.3\%) reported 1-2 hrs of using pencils/pens daily. Moreover, $36.2 \%$ of students reported that phone use increased their levels of stress and anxiety.

\section{Association between DASH score and independent variables}

Table 3 shows the results of the regression analysis of associated variables and the DASH scores. The table only shows the significant results. The following variables were associated with upper limb disability: presence of musculoskeletal problems, not living with their families, using public transport (bus), daily housekeeping, several 
Table 2 Smart phone usage information $(\mathrm{N}=1929)$ and mean DASH score and standard deviations [M (SD)]

\begin{tabular}{|c|c|c|}
\hline Variable & $\mathbf{N}(\%)$ & $M(S D)$ \\
\hline \multicolumn{3}{|c|}{ Number of smartphones } \\
\hline I & $1643(85.2)$ & $29.24(9.2)$ \\
\hline 2 & $218(11.3)$ & $29.78(12.3)$ \\
\hline$\geq 3$ & $68(3.5)$ & $30.21(15.7)$ \\
\hline \multicolumn{3}{|c|}{ Number of years using smartphone } \\
\hline $\mathrm{I}-2$ & $556(28.8)$ & $28.08(10.3)$ \\
\hline $3-4$ & $502(26)$ & $30.55(9.4)$ \\
\hline$\geq 5$ & $87 \mid(45.6)$ & $33.89(9.7)$ \\
\hline \multicolumn{3}{|c|}{ Daily hours of smartphone use } \\
\hline $\mathrm{I}-3$ & $536(27.8)$ & $28.64(9.7)$ \\
\hline $4-6$ & $744(38.6)$ & $31.93(9.3)$ \\
\hline $7-9$ & $261(13.5)$ & $33.87(10.4)$ \\
\hline$\geq 10$ & $388(20.1)$ & $35.6(10.7)$ \\
\hline \multicolumn{3}{|c|}{ Hand use of smartphone } \\
\hline Single hand & $1239(64.2)$ & $33.32(10.5)$ \\
\hline Both hands & $690(35.8)$ & $28.75(9.9)$ \\
\hline \multicolumn{3}{|c|}{ Usage of smartphone before sleep } \\
\hline Yes & $1752(90.8)$ & $33.15(10.0)$ \\
\hline No & $177(9.2)$ & $29.11(9.9)$ \\
\hline \multicolumn{3}{|c|}{ Usage of smartphone during transportation } \\
\hline Yes & I $584(82.1)$ & $29.0(10.1)$ \\
\hline No & $345(17.9)$ & $29.38(9.7)$ \\
\hline \multicolumn{3}{|c|}{ Reasons for using smartphone } \\
\hline Leisure & $|23|(63.8)$ & $29.78(10.5)$ \\
\hline Education & $997(51.7)$ & $28.88(9.3)$ \\
\hline Social communication & $1298(67.3)$ & $35.74(11.0)$ \\
\hline Work & $407(21.1)$ & $29.67(11.2)$ \\
\hline \multicolumn{3}{|c|}{ Increased level of anxiety with smart phone usage } \\
\hline Yes & $698(36.2)$ & $33.38(10.7)$ \\
\hline No & $641(33.2)$ & $27.25(9.1)$ \\
\hline Do not know & $590(30.6)$ & $29.11(9.6)$ \\
\hline \multicolumn{3}{|c|}{ Daily hours of computer use } \\
\hline 0 & $618(32)$ & $28.24(9.7)$ \\
\hline $\mathrm{I}-2$ & $829(43)$ & $28.58(9.3)$ \\
\hline $3-4$ & $268(13.9)$ & $29.22(10.0)$ \\
\hline$\geq 5$ & $214(11.1)$ & $29.70(10.2)$ \\
\hline \multicolumn{3}{|c|}{ Daily hours of pencil/pen use } \\
\hline 0 & $90(4.7)$ & $28.76(10.8)$ \\
\hline $\mathrm{I}-2$ & $1105(57.3)$ & $29.07(9.7)$ \\
\hline $3-4$ & $477(24.7)$ & $29.23(9.8)$ \\
\hline$\geq 5$ & $257(13.3)$ & $29.71(12.2)$ \\
\hline
\end{tabular}

characteristics relating to smartphone use (time since start of use, use with a single hand, use before sleep, and use for social communication) and the presence of anxiety from using a smartphone. The total score of upper limb disability increased on average by 3.6 if the subject had a musculoskeletal disorder when holding other independent variables constant. The same expression applies for other significant variables and the $\beta$ value related to it.

\section{Discussion}

The aim of this study was to identify the prevalence and risk factors of upper limb pain and disability among university students using the DASH score. The prevalence of upper limb pain and disability among university students was $24 \%$. The overall prevalence in this study was lower than most of the prevalence findings reported previously. Many researchers reported moderate to higher prevalence rate (42-96\%) of upper extremity discomfort, pain and disability due to computer use, evaluated by using different disability severity scales. ${ }^{10,11,14-16,29}$ Many reasons may explain the discrepancy in the prevalence reported among different studies, such as the variation of outcome measurements used, the differences in dependent variables examined in each study (upper extremity versus general musculoskeletal discomfort), and the context mentioned in the questions (eg while using the computer versus after using the computer).

Another primary finding of the present study indicates that several factors significantly contribute to the upper limb disability among university students. These factors were mainly related to the use of smartphones, computer use, and other factors related to the presence of other musculoskeletal problems, such as living alone (not with the family), using public transport (buses), and daily hours of housekeeping.

There is anecdotal and observational evidence that college students make excessive use of technology both within and outside the campus. Excessive use of smartphones for academic and non-academic purposes was reported to impact their level of concentration and academic performance during the course of study. Furthermore, utilization of smartphones and computers has become a trend among college students, which could have a detrimental effect on their posture, causing long-term upper limb disability and limitations..$^{13,24,25,27}$ One of the most interesting results that were revealed in the present study is the increased incidence of upper limb disability among university students with the increased use of smartphones, corroborating previous 
Table 3 Predictors of DASH scores $(n=1929)$, results of regression analysis

\begin{tabular}{|l|l|l|l|}
\hline Independent variables & $\boldsymbol{\beta}$-coefficient & $\boldsymbol{t}$-value & Significance ( $\boldsymbol{p})$ \\
\hline Student lives with family (No) & 2.108 & 3.452 & 0.001 \\
Presence of musculoskeletal disorders & 3.584 & 2.799 & 0.005 \\
Years using phone & 0.334 & 2.058 & 0.040 \\
Daily hours using phone & 0.243 & 3.091 & 0.002 \\
Using phone with one hand & 1.229 & 2.753 & 0.006 \\
Using phone before sleep & 1.612 & 2.065 & 0.039 \\
Using phone for social communication & 1.168 & 2.210 & 0.027 \\
Upper limb complaints and anxiety (yes) & 1.797 & 7.049 & 0.000 \\
Bus transportation to university & 1.073 & 1.983 & 0.048 \\
Daily hours of housekeeping & 1.269 & 2.121 & 0.034 \\
\hline
\end{tabular}

research. For instance, a cross-sectional study of 102 college students, who were divided into non-users, low and high users of smartphones, showed a significantly more severe pain in the dominant hand of the high smartphone users compared to non-users. ${ }^{37}$ Additionally, a study on 34 adults classified into groups according to the duration of smartphone use found that hand pain and fatigue were aggravated with longer smartphone use. The visual analog scale was used to measure the level of pain in this study. ${ }^{38}$ Similarly, a study of 149 subjects within an age range of 18-40 years, who were classified as frequent and infrequent smartphones texters, found that DASH scores were significantly higher in the frequent texter group. ${ }^{39}$

Furthermore, the results of the present study showed that single-handed smartphone users had more upper limb complaints than two-handed users, as also supported by previous research. Lee and colleagues compared the effects of phone handling with one hand versus both hands in a group of asymptomatic women (20-22 years). ${ }^{40}$ A pressure-induced pain was significantly more frequent in one-handed users than in two-handed users. Another study tested the hypothesis that holding a smartphone screen with two hands may lead to decreased hand pain. Ten right-handed participants completed tasks using either one- or two-handed grip on a smartphone, confirming the suggested hypothesis. ${ }^{41}$ Therefore, these findings provide insight on the potential risks and pathologies caused by the misuse of smartphones and emphasize the importance of taking prophylactic measures while using a smartphone, such as proper timing, correct posture, and rest breaks. These findings could also be considered by smartphone companies to design new devices, taking into account size and keypad design (layout and size) that could be less harmful to the musculoskeletal system.
The present study showed a significant correlation between anxiety related to smartphone use and DASH scores, in agreement with previous research. Ring et al reported a positive correlation between self-reported upper limb disability, as measured by the DASH score, and the level of anxiety in a group of 235 individuals. $^{31}$ In addition, a cross-sectional study of 120 individuals suffering from upper limb disability reported that the DASH score was correlated with the score of Hamilton anxiety scales. ${ }^{30}$ These findings indicate the importance of physical, as well as psychosocial, interventions for this population. However, one of the limitations of the current study is that anxiety was assessed using one simple question, as a part of the survey questionnaire, and not by using a standardized anxiety scale.

Our results showed that upper limb disability increased with the use of public transport to the university. As such, if the students are using public transport, they are likely to spend more time sitting on the bus using their smartphone for entertainment and socialization. The majority of students spend an average of 4 hrs every day traveling to and from the university using busy means of public transport with uncomfortable chairs. This was supported by a study of 285 patients with upper limb disability, who indicated upper limb pain onset within 15 mins of boarding public buses compared to participants without symptoms. ${ }^{15}$ It seems that public transport vibration might also be related to the development of disability symptoms. Most Jordanian students tend to use their phones during their long trip in public transport, which may have adverse effects on their neck and upper limbs as revealed in a recent study. 38

Furthermore, the results of this study also showed that students with musculoskeletal disorders had a significantly 
higher level of upper limb disability, as also shown by previous studies., 8 10-12,17 The European working conditions survey (1995-2010) revealed that individuals with musculoskeletal disorders were at excessive risk of pain and symptoms in the upper limbs. ${ }^{17}$ Similarly, Feuerstein et al reported that upper limb disability was associated with musculoskeletal disorder complaints. ${ }^{8}$ Therefore, there is a need to evaluate specific interventions for students who suffer from musculoskeletal disorders, since these disorders would affect students' quality of life and future career.

Another interesting finding of this study was the higher upper limb disability in students living alone and participating more in housekeeping tasks. International students and students whose families live far away from the universities usually lived in student apartments or dorms. The majority of students use public transport, participate in housekeeping activities and use smartphones to communicate with their family at a higher rate compare to the other students. The coexistence of these factors (ie living without family or social support) could be responsible for the increased risk of upper limb disability among these students, as supported by recent studies. One study illustrated that upper limb disability measured by DASH scores was significantly associated with the lack of social support. ${ }^{18}$ In addition, previous research highlighted the effect of housekeeping activities on upper limb disability. ${ }^{19}$ A study of 1108 Singaporean and Chinese individuals found that upper limb strain injury was associated with housework activities. ${ }^{20}$ While another study showed that upper limb strain injury was directly associated with the number of daily hours spent in housekeeping. ${ }^{21}$ Housework activities commonly involve small-to-large biomechanical loads, are characterized by repetitive movements and are frequently associated with high arm/hand force with awkward postures, which may exacerbate upper limb disability. ${ }^{19-21}$

Several limitations exist in the current study. Stress and anxiety arising from smartphone use were assessed using a single question, which might not sufficient to describe the psychological effect of smartphone use on students. Additionally, the study was conducted only in universities located in the north of the country, which may present different living conditions compared to universities located in the middle or south parts of the country.

Additional research is needed to investigate the impact of other factors on upper limb disability in this population, such as body mass index, sex, and age, having children, physical fitness and types of housekeeping activities. Additional factors need to be examined in working students, such as the type of job and the level of pressure at work. Future research should also investigate the effectiveness of different prevention and intervention measures on upper limb disability.

\section{Conclusions}

A range of potential risk factors of upper limb disability and pain among college students was investigated. The novel aspect of the present study was to examine the effect of both smartphone and computer use along with other potential risk factors. Our findings may be used globally to promote health and wellbeing of university students, improve their academic performance, and assist in developing appropriate interventions. The identification of high-risk groups will facilitate early diagnosis, screening and prevention of upper limb disability among university students.

Further research is required to corroborate the present findings and identify modifiable predictors of poor outcomes. It is important to identify prognostic and risk factors, particularly modifiable factors that may influence management and intervention strategies. This would enable rehabilitation therapists to provide better advice to high-risk patients and could be useful in the development of targeted management strategies, as well as public and occupational health initiatives.

\section{Ethics approval and consent to participate}

The study was approved by the institutional review board of King Abdullah University Hospital and the faculty of research at Jordan university of science and technology. A written consent was obtained from all participants prior to the recruitment in the study.

\section{Availability of data and material}

The datasets generated and/or analyzed during the current study are not publicly available due to privacy reasons, but are available from the corresponding author on reasonable request.

\section{Acknowledgments}

The authors are grateful to the Deanship of Research at Jordan University of Science and Technology for study funding through grant number 302017 and the Deanship of Scientific Research at King Saud University for study funding through the Vice Deanship of Scientific Research Chairs, King Saud University. The funding bodies were not involved 
in the study design, collection, analysis or interpretation of data, or in the writing of the manuscript and the decision to submit the article for publication.

\section{Author contributions}

All authors contributed towards data analysis, drafting and critically revising the paper, gave final approval of the version to be published, and agreed to be accountable for all aspects of the work.

\section{Disclosure}

The authors report no conflicts of interest in this work.

\section{References}

1. Walker-Bone K, Palmer KT, Reading I, Coggon D, Cooper C. Prevalence and impact of musculoskeletal disorders of the upper limb in the general population. Arthritis Rheum. 2004;51(4):642-651.

2. Huisstede BM, Bierma-Zeinstra SM, Koes BW, Verhaar JA. Incidence and prevalence of upper-extremity musculoskeletal disorders. A systematic appraisal of the literature. BMC Musculoskelet Disord. 2006;7:7.

3. Palmer KT, Calnan M, Wainwright D, et al. Upper limb pain in primary care: health beliefs, somatic distress, consulting and patient satisfaction. Fam Pract. 2006;23(6):609-617.

4. Borghouts JA, Koes BW, Bouter LM. The clinical course and prognostic factors of non-specific neck pain: a systematic review. Pain. 1998;77(1):1-13.

5. Urwin M, Symmons D, Allison T, et al. Estimating the burden of musculoskeletal disorders in the community: the comparative prevalence of symptoms at different anatomical sites, and the relation to social deprivation. Ann Rheum Dis. 1998;57(11):649-655.

6. Picavet HS, Hazes JM. Prevalence of self reported musculoskeletal diseases is high. Ann Rheum Dis. 2003;62(7):644-650.

7. Cole DC, Hudak PL. Prognosis of nonspecific work-related musculoskeletal disorders of the neck and upper extremity. Am J Ind Med. 1996;29(6):657-668

8. Feuerstein M, Huang GD, Haufler AJ, Miller JK. Development of a screen for predicting clinical outcomes in patients with work-related upper extremity disorders. J Occup Environ Med. 2000;42(7):749-761.

9. Karels CH, Bierma-Zeinstra SM, Burdorf A, Verhagen AP, Nauta AP, Koes BW. Social and psychological factors influenced the course of arm, neck and shoulder complaints. J Clin Epidemiol. 2007;60(8):839-848.

10. Hupert N, Amick BC, Fossel AH, Coley CM, Robertson MM, Katz $\mathrm{JN}$. Upper extremity musculoskeletal symptoms and functional impairment associated with computer use among college students. Work. 2004;23(2):85-93.

11. Katz JN, Amick BC, Carroll BB, Hollis C, Fossel AH, Coley CM. Prevalence of upper extremity musculoskeletal disorders in college students. Am J Med. 2000;109(7):586-588.

12. Katz JN, Amick III BC, Hupert N, et al. Assessment of upper extremity role functioning in students. Am J Ind Med. 2002;41(1):19-26.

13. Schlossberg EB, Morrow S, Llosa AE, Mamary E, Dietrich P, Rempel DM. Upper extremity pain and computer use among engineering graduate students. Am J Ind Med. 2004;46(3):297-303.

14. Menéndez CC, Amick III BC, Jenkins M, et al. Upper extremity pain and computer use among engineering graduate students: a replication study. Am J Ind Med. 2009;52(2):113-123.

15. de Saboya Lenzi LG, Myiamoto Meirelles L, Baptista Gomes Dos Santos J, Faloppa F, Raduan Neto J. Triggering of carpal tunnel syndrome symptoms in patients using urban public transportation. HAND. 2016;11(3):257-261.
16. Whibley D, Martin KR, Lovell K, Jones GT. A systematic review of prognostic factors for distal upper limb pain. Br J Pain. 2015;9 (4):241-255

17. Montano D. Upper body and lower limbs musculoskeletal symptoms and health inequalities in Europe: an analysis of cross-sectional data. BMC Musculoskelet Disord. 2014;15:285.

18. Nota SP, Spit SA, Oosterhoff TC, Hageman MG, Ring DC, Vranceanu A-M. Is social support associated with upper extremity disability?. Clin Orthop Relat Res. 2016;474(8):1830-1836. doi:10.1007/s11999-016-4892-2

19. Yang Z, Cheung TWC. The inclusion of homemakers as an occupation amongst people with upper limb repetitive stress injuries. Work. 2016;55(1):181-186.

20. Apostoli P, Sala E, Curti S, Cooke RM, Violante FS, Mattioli S. Loads of housework? Biomechanical assessments of the upper limbs in women performing common household tasks. Int Arch Occup Environ Health. 2012;85(4):421-425.

21. Sala E, Mattioli S, Violante F, Apostoli P. Risk assessment of biomechanical load for the upper limbs in housework. Med Lav. 2007;98 (3):232-251.

22. Bruls VE, Bastiaenen CH, de Bie RA. Non-traumatic arm, neck and shoulder complaints: prevalence, course and prognosis in a Dutch university population. BMC Musculoskelet Disord. 2013;14(1):8.

23. Calik BB, Yagci N, Gursoy S, Zencir M. Upper extremities and spinal musculoskeletal disorders and risk factors in students using computers. Pak J Med Sci. 2014;30(6):1361.

24. Gerr F, Marcus M, Ensor C, et al. A prospective study of computer users: I. Study design and incidence of musculoskeletal symptoms and disorders. Am J Ind Med. 2002;41(4):221-235.

25. Marcus M, Gerr F, Monteilh C, et al. A prospective study of computer users: II. Postural risk factors for musculoskeletal symptoms and disorders. Am J Ind Med. 2002;41(4):236-249.

26. Gerr F, Marcus M, Monteilh C. Epidemiology of musculoskeletal disorders among computer users: lesson learned from the role of posture and keyboard use. J Electromyogr Kinesiol. 2004;14 (1):25-31.

27. Gustafsson E, Johnson PW, Hagberg M. Thumb postures and physical loads during mobile phone use-A comparison of young adults with and without musculoskeletal symptoms. J Electromyogr Kines. 2010;20(1):127-135.

28. Vranceanu A-M, Safren S, Zhao M, Cowan J, Ring D. Disability and psychologic distress in patients with nonspecific and specific arm pain. Clin Orthop Relat Res. 2008;466(11):2820-2826.

29. Chang C, Amick III BC, Menendez CC, et al. Daily computer usage correlated with undergraduate students' musculoskeletal symptoms. Am J Ind Med. 2007;50(6):481-488.

30. Hamilton AG, Jacobs K, Orsmond G. The prevalence of computerrelated musculoskeletal complaints in female college students. Work. 2005;24(4):387-394.

31. Ring D, Kadzielski J, Fabian L, Zurakowski D, Malhotra LR, Jupiter JB. Self-reported upper extremity health status correlates with depression. JBJS. 2006;88(9):1983-1988.

32. Bagheri F, Ebrahimzadeh MH, Moradi A, Bidgoli HF. Factors associated with pain, disability and quality of life in patients suffering from frozen shoulder. Archiv Bone Joint Surg. 2016;4(3):243.

33. Alotaibi NM, Aljadi SH, Alrowayeh HN. Reliability, validity and responsiveness of the Arabic version of the Disability of Arm, Shoulder and Hand (DASH-Arabic). Disabil Rehabil. 2016;38 (25):2469-2478.

34. Bilberg A, Bremell T, Mannerkorpi K. Disability of the Arm, Shoulder and Hand questionnaire in Swedish patients with rheumatoid arthritis: a validity study. $J$ Rehabil Med. 2012;44(1):7-11.

35. Alberta FG, ElAttrache NS, Bissell S, et al. The development and validation of a functional assessment tool for the upper extremity in the overhead athlete. Am J Sports Med. 2010;38(5):903-911. 
36. Huisstede BM, Feleus A, Bierma-Zeinstra SM, Verhaar JA, Koes BW. Is the disability of arm, shoulder, and hand questionnaire (DASH) also valid and responsive in patients with neck complaints. Spine. 2009;34(4):E130-E138. doi:10.1097/BRS.0b013e318195a28b

37. Inal EE, DemIrc IK, CetInturk A, Akgonul M, Savas S. Effects of smartphone overuse on hand function, pinch strength, and the median nerve. Muscle Nerve. 2015;52(2):183-188.

38. Kim S, Koo S. Effect of duration of smartphone use on muscle fatigue and pain caused by forward head posture in adults. $J$ Phys Ther Sci. 2016;28(6):1669-1672.
39. Akkaya N, Dogu B, Unlu Z, et al. Ultrasonographic evaluation of the flexor pollicis longus tendon in frequent mobile phone texters. $\mathrm{Am} \mathrm{J}$ Phys Med Rehabil. 2015;94(6):444-448.

40. Lee M, Hong Y, Lee S, et al. The effects of smartphone use on upper extremity muscle activity and pain threshold. J Phys Ther Sci. 2015;27(6):1743-1745.

41. Trudeau MB, Asakawa DS, Jindrich DL, Dennerlein JT. Two-handed grip on a mobile phone affords greater thumb motor performance, decreased variability, and a more extended thumb posture than a onehanded grip. Appl Ergon. 2016;52:24-28.

\section{Publish your work in this journal}

The Journal of Pain Research is an international, peer reviewed, open access, online journal that welcomes laboratory and clinical findings in the fields of pain research and the prevention and management of pain. Original research, reviews, symposium reports, hypothesis formation and commentaries are all considered for publication. The manuscript management system is completely online and includes a very quick and fair peer-review system, which is all easy to use. Visit http:// www.dovepress.com/testimonials.php to read real quotes from published authors. 